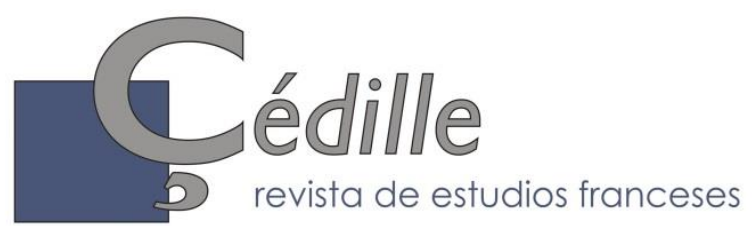

\title{
Boris Vian en collage, al rebufo del centenario*
}

\author{
Ainhoa CusÁcovich ToRRES \\ Universidad de Valladolid \\ ainhoa.cusacovich@uva.es \\ https://orcid.org/oooo-0oo1-9167-5393
}

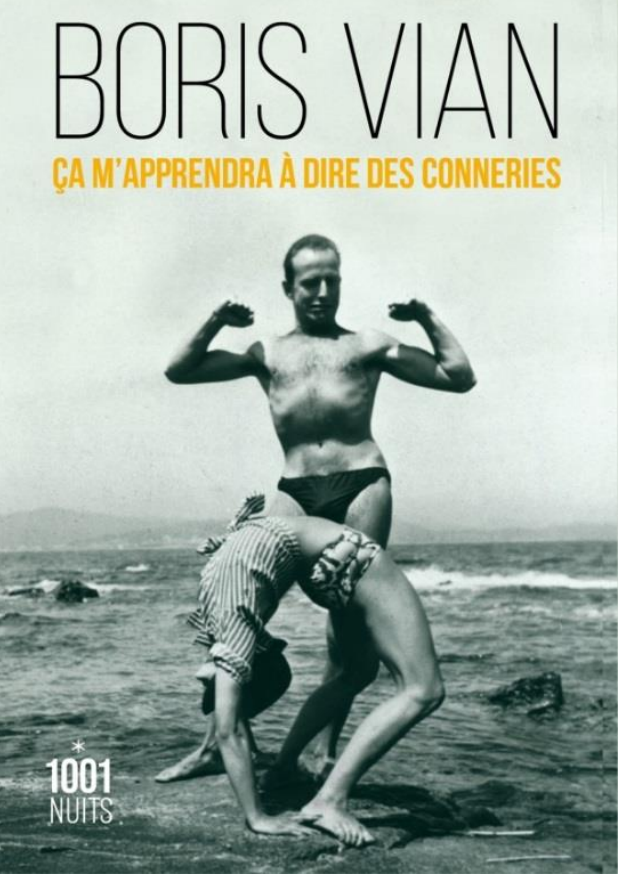

El centenario del nacimiento de Boris Vian ha inspirado a autores y editores que han tomado el 2020 como un momento de homenaje al conocido autor ${ }^{1}$. Cien años han pasado desde el nacimiento del novelista -entre otras profesiones- que supo condensar en 39 años una producción tan variada como ecléctica.

Novelas, crónicas, obras de teatro, poemas o canciones fueron algunas de las creaciones literarias de Vian, marcadas por una metodología que se acerca al collage, incluyendo en su obra una estética cercana al cómic, a la lírica romántica o a los libros de recetas de Gouffé2. Cualquier elemento de la realidad tiene su utilidad en la obra vianesca, muy influenciada por el cine y el jazz, que parece compuesta por piezas que se van ensamblando. Así, nos explica Marc Lapprand en su «Sept mots clés pour expliquer sa postérité» (Lapprand, 2004: 7-12), su producción

* Acerca del libro de Florian Madisclaire, Boris Vian. Ça m'apprendra à dire des conneries (París, Librairie Arthème Fayard - Mille et une Nuits, 2020, 117 p. ISBN: 978-2-7555-07638).

${ }^{1}$ Nicole Bertolt ha presentado en este mismo año, 2020, su obra Correspondances, 19321959, un compendio de cartas del autor, postales y correspondencia de otros tipos, siguiendo una clasificación cronológica y temática.

2 Jules Gouffé (1807-1877) fue un chef francés admirado por el propio Vian, cuyas recetas constituyen, incluso, materia de novelas como L'Écume des jours (1947). 
viene marcada por el humor, la excentricidad, el eclecticismo, el jazz, la sensualidad, el profesionalismo y la libertad. Publicar una obra homenaje al autor implica, por lo tanto, una capacidad para no dejarse llevar por las etiquetas ni las clasificaciones; un respeto de la libertad creadora de Vian que marca acercamientos tan curiosos como el del orden alfabético de sus temas, adoptado por Noël Arnaud en un número especial que dirigió en la revista Obliques, con su «Boris Vian de A à Z» (1976: 1-2).

El genio incomprendido en su época tuvo un talento destacado para cultivar muchos campos y se mostró siempre intrépido e innovador. Vian fue: ingeniero, poeta, novelista, dramaturgo, traductor, trompetista, redactor de crítica musical, letrista e incluso actor y cantante esporádicamente. Fue un escritor único, anticipado a su tiempo y tan «collage» como su propia obra, Vian es descrito de forma brillante por su amigo Henri Salvador: «Il avait un trop gros cerveau. Il n'était ni d'hier ni d'aujourd'hui, mais de demain» (Arnaud, 1981: 395).

El compilador del presente volumen, que lleva el título provocador de Ça m'apprendra à dire des conneries, ha recogido citas del conjunto de la ingente producción vianesca, seleccionando algunas de novelas, como es el caso de l'Herbe Rouge, l'Écume des Jours, J'irai cracher sur vos tombes, l'Arrache-Cour, Et on tuera tous les Affreux o l'Automne à Pékin. Algunas de las citas han sido extraídas de obras de teatro como Le Goûter des Généraux o Équarrissage pour tous. Incluso, en ese afán por cubrir lo caleidoscópico de su producción, se ha servido de documentos recopilatorios de poemas, escritos críticos, ensayos o cartas personales del autor ya recogidas en la obra citada anteriormente, Correspondances (2020).

Tras un breve prefacio y las notas sobre la edición (p. 6), el responsable de la recopilación, Florian Madisclaire, presenta una serie de extractos tomados de las obras anteriormente citadas. Sin un orden o clasificación concretos, la polifonía ecléctica de Boris Vian se muestra mejor que nunca, saltando de un tema a otro, de un poema a una carta, de una novela a una crónica, para dejarnos ver cada una de esas caras del controvertido autor. La obra finaliza, antes de pasar a la bibliografía, con un capítulo que presenta una biografía del autor, «Tentative de biographie» (pp. 97-114), establecida por la Directora del patrimonio de Boris Vian, Nicole Bertolt. Un abanico de genialidad como la propia vida de Vian: breve, intensa y genial.

Esta constituye, pues, la materia prima de una obra breve y aparentemente ligera: novelas, compendios de poemas, tratados, obras de teatro, cartas personales, crónicas o incluso canciones; toda la obra de Boris Vian comparte una temática y una estilística propia, ácida y tierna, hiriente y romántica. En efecto, su creación se desgrana en multitud de temas que resultan difícilmente plasmables en una obra tan sintética como la que estamos analizando. Sin embargo, en una lectura atenta, sí llegamos a encontrar las grandes cuestiones que sobrevuelan novelas, obras de teatro, cartas, canciones o poemas. 
El primero de los temas que se desprenden de los extractos escogidos es el de la libertad. Este deseo de libertad, junto con el individualismo al que va unido, constituye una de las señas de identidad de Vian, que Madisclaire expone en la siguiente cita de Belle Époque (1982): «Qui veut acquérir l'immortalité doit-il donc s'astreindre à couler son ouvre dans le moule rigide du langage littéraire ? S'il gagne ainsi l'éclat du marbre, il en conserve la froideur» (p. 12). La libertad responde, en Vian, a una necesidad, tanto en lo personal como en lo literario, a un rechazo de estereotipos y clasificaciones innecesarias. La búsqueda de esta libertad no culmina en él hasta que no se convierte en miembro del colegio de Patafísica3. Esta escuela resulta para él la materialización del individualismo, un lugar en el que la frase de Colin pronunciada en la novela L'Écume des jours (1947) cobra más sentido que nunca: «Ce qui m'intéresse, ce n'est pas le bonheur de tous les hommes, c'est celui de chacun» (p. 13).

Otro de los temas que no podemos obviar en referencia a Vian es el humor; cuestión que utiliza como herramienta, pero también sobre la que nos ofrece reflexiones como: «L'humour c'est la politesse du désespoir» (p. 16). El sentido del humor se encuentra siempre presente en el modo de vida del novelista: forma parte de su discurso; pero es asimismo lo que rige su lógica. En L'Écume des jours, Vian hace referencia a este tema: buscar en el humor las respuestas más profundas que, planteadas desde la seriedad, resultan menos fructíferas. Así, afirma el doctor Mangemanche en la novela, «Quand vous faites une plaisanterie, vous avez intérêt à avoir l'air plus sérieux et à trouver des réponses plus spirituelles» (Vian, 1996: 224).

Por otra parte, existe en toda la creación vianesca una obsesión por la juventud, por ese estado tan limitado en el tiempo en el que somos nuestra verdadera esencia. En esos años estaríamos, según el propio autor, más abiertos a seguir nuestras aspiraciones y más conectados con la vida. De esta forma, recalca Madisclaire retomando una cita de Les Bâtisseurs d'empire ou le Schmürz (1959), «C'est les jeunes qui se souviennent. Les vieux, ils oublient tout» (p. 35).

Con todo, el tema predominante en la producción artística de Vian es el amor, junto con la pasión, como únicas cuestiones esenciales en la vida. Existe, en cada una de sus obras, una visión polifónica del amor como sentimiento múltiple, evolutivo y plural. En Écrits pornographiques (1980) señala Madisclaire- podemos observar el valor que Vian otorga a los sentimientos, como motor de la humanidad y, en ocasiones, único motivo real para la existencia:

\footnotetext{
3 El Colegio de Patafísica, del que Vian fue miembro activo, «sátrapa», se fundó el 11 de mayo de 1948 basándose en la obra de Alfred Jarry Gestes et opinions du docteur Faustroll, pataphysicien, de 1898. En ella aparece la definición de esta «ciencia»: «La pataphysique est la science des solutions imaginaires, qui accorde symboliquement aux linéaments les propriétés des objets décrits par leur virtualité» (Jarry, 1972: 668-669).
} 
Les sentiments et les sensations qui ont l'amour pour commune origine, sous la forme brute du désir comme sous les formes les plus raffinées du flirt intellectuel avec citations et philosophie ambiante sont sans nul doute, avec ceux qui se rattachent aux choses de la mort, si voisins d'ailleurs, les plus intenses et les plus violemment ressentis par l'humanité (p. 8).

Conocido de todos es el desprecio por la guerra que manifiesta Vian, como el mayor engaño que la humanidad ha llevado a cabo consigo misma. El antimilitarismo se encuentra presente a lo largo de toda la creación literaria y artística de Vian, siendo en algunas de sus obras de teatro, como en L'Équarrissage pour tous (1948), donde encontramos en mayor medida la expresión del pacifismo y la ridiculización de todo acto bélico. Como recoge Madisclaire con las palabras mismas de Vian, «La guerre, cette chose grotesque, a ceci de particulier (entre autres) qu'elle est envahissante et importune, et ceux qu'elle amuse se croient en général fondés à l'étendre à ceux qu'elle n'amuse pas. C'est une des multiples figures de l'intolérance, et la plus destructrice» (p.58).

El lenguaje constituye el material lúdico de Vian: su materia prima, manejada a través del humor y la ironía. Refuerza, de este modo, el juego de lo cómico, rompiendo con los convencionalismos. Las palabras se transforman, haciendo gala de su «langage univers» 4 , crean una atmósfera en la que reinan la excentricidad, lo lúdico y la experimentación.

Ainsi conçue, la loufoquerie consiste en une façon de tout raconter comme si le langage, sans avoir à se conformer à une réalité indépendante de lui, créait son propre univers; les adeptes du genre sont ceux qui choisissent d'y vivre. Essentiellement verbal à l'origine, cet humour finit par devenir presque une philosophie et un mode de vie. Les loufoques habitent un monde à part où le mot est roi et tout se réduit à des jeux -des jeux de mots pour ses sujets fidèles (Noakes, 1964: 47).

Florian Madisclaire nos propone decenas de ejemplos de este juego con el lenguaje, como el extraído de la novela L'Herbe rouge (1950): «Je ne peux pas te dire que tu es belle comme le jour, dit Lazuli, ça dépend des jours. Mais une lanterne japonaise, c'est toujours joli» (p. 52).

Dado lo ecléctico de la selección, los destinatarios de Ça m’apprendra à dire des conneries pueden ser tanto personas que se acerquen a la figura de Vian por primera vez como conocedores del autor, que sabrán captar el estilo y los grandes temas que sobrevuelan todas sus obras -sean del tipo que sean-. Entre estos expertos se encuentran aquellos que Roulmann

${ }_{4}^{4}$ Se trata de una expresión propuesta por Jacques Bens en el posfacio de L'Écume des Jours (1963), explicando así la visión lúdica y metafórica del lenguaje vianesco. 
describe como «vianophiles», seguidores de la obra de Vian y verdaderos coleccionistas de cualquier creación literaria del autor:

Le «vianophile» est une espèce rare de lecteur, éventuellement bibliophile, qui s'intéresse aux éditions passées et présentes des œuvres et des traductions de Boris Vian, ainsi qu'aux sources et références biographiques sur notre auteur. Sans se prendre trop au sérieux et en évitant l'obsession de Chick pour Jean-Sol Partre dans l'Écume des jours, le vianophile peut vouloir rassembler les éditions les plus anciennes et rares de son auteur préféré, mais aussi chercher à détenir plus simplement les «meilleures » éditions disponibles (Roulmann, 2004: 98).

En efecto, esta recopilación sui generis se nos presenta como un aperitivo a la inmensa creación literaria vianesca, una serie de citas sin orden, estructura o temática en concreto, que permiten apreciar lo variado de la producción del autor. Dependerá, pues, de nuestro grado de conocimiento de Vian y su obra que podamos entrever más o menos matices en cada una de las joyas que suponen los extractos escogidos. Uno puede, sin ser experto, disfrutar de la inteligencia comprimida en citas que responden a temas diferentes, pero que guardan la esencia vianesca, el humor ácido de quien observa el mundo desde una mente crítica y llena de lucidez.

\section{REFERENCIAS BIBLIOGRÁFICAS}

ARNAUD, Noël (1976): «Boris Vian de A à Z». Obliques 8-9, numéro spécial, 1-2 ARNAUd, Noël (1981): Les vies parallèles de Boris Vian. París, Christian Bourgois. BENS, Jacques (1963): «Un langage univers» [Postface], in Boris Vian, $L^{\prime}$ Écume des jours. París, Union générale d'éditions (Le monde en 10/18), 175-184.

JARRY, Alfred (1972): Gestes et opinions du docteur Faustroll, pataphysicien, in Euvres complètes. Paris, Gallimard (Bibliothèque de la Pléiade), t. I.

LAPPRAND, Marc (2005) : «Sept mots clés pour expliquer sa postérité». Les vies de Boris Vian. Les Collections du Magazine Littéraire, hors-série, 6, nov. 2004-janv. 2005, 7-12.

NOAKES, David (1964): Boris Vian. París, Éditions Universitaires (Classiques du XXe siècle).

RoulmanN, François (2005) : «Vianophilie pour tous». Les vies de Boris Vian. Les Collections du Magazine Littéraire, hors-série, 6, nov. 2004-janv. 2005, 98.

ViAN, Boris (1996 [1947]): L'Écume des Jours. Notations de Gilbert Pestureau. París, Librairie générale française (Livre de poche). 